Scientił studia, São Paulo, v. 6, n. 1, p. 83-96, 2008

\title{
st \\ Aspectos cognitivos e sociais das práticas científicas
}

\author{
Hugh LAGeY
}

\begin{abstract}
$\ddot{\sim}$
RESUMO

Será um aspecto constitutivo dos juízos de aceitabilidade cognitiva de teorias o fato de serem feitos sob certas relações sociais que incorporam valores sociais específicos cultivados pelos pesquisadores (Helen Longino)? Ou será que fazer juízos corretos desse tipo é apenas uma conseqüência de interações sociais que ocorrem sob essas relações (Philip Kitcher)? Embora de maneira geral subscreva o segundo ponto de vista, faço uma distinção, ausente dos escritos de Longino e Kitcher, entre aceitação correta e endossamento (endorsement) de uma teoria, e defendo a tese de que a concepção de Longino aplica- se ao endossamento.
\end{abstract}

Palavras-chave $\bullet$ Valores cognitivos. Valores sociais. Objetividade. Longino. Kitcher.

Apreciação de teoria científica. Metodologia científica.

As práticas científicas respondem a interesses tanto cognitivos (epistêmicos) quanto sociais/éticos. Entretanto, diz-se freqüentemente que o conhecimento obtido por elas e as teorias, nas quais esse conhecimento se expressa, não têm, ou não devem ter, a marca indelével de valores. Afirma-se que o "centro" da ciência não é maculado por valores: teorias são apreciadas (appraised) pelo peso da evidência a seu favor, e os valores não têm papel algum na justificação de decisões metodológicas corretamente tomadas. É claro que os valores cognitivos, ou critérios para a apreciação de teorias científicas, são indispensáveis (cf. Lacey, 2008). Porém, valores cognitivos são distintos de valores sociais, éticos e de outros tipos, e os critérios de sua identificação não dependem de compromissos com valores não-cognitivos (cf. Lacey, 2003a). É aos valores não-cognitivos que se nega um papel na apreciação teórica e nas decisões metodológicas fundamentais.

Nas práticas científicas assim interpretadas, há momentos em que os valores podem ter papéis legítimos (cf. Lacey, 1999, p. 17-9), particularmente quando o conhecimento científico é aplicado tecnologicamente, e escolhas específicas são feitas a respeito dos fenômenos a serem investigados e dos métodos a serem utilizados. Afirma-se contudo (por razões bem conhecidas) que o centro da ciência permanece 
imaculado por valores envolvidos nas decisões feitas nesses momentos. Deve também permanecer imaculada pelos interesses pessoais dos cientistas e pelo fato de que as práticas científicas não podem ser realizadas sem as condições materiais, econômicas e institucionais adequadas e, portanto, sem a generosidade de instituições não-científicas (agências estatais, empresas etc.), que em geral incorporam valores sociais não subordinados ao valor da aquisição de entendimento científico. Valores sociais, éticos e pessoais podem legitimamente afetar não apenas decisões feitas nos momentos nãocentrais, mas também a dinâmica e a textura das práticas científicas: quando, onde, e por quem são conduzidas, quão rápida e amplamente são desenvolvidas, e se são acolhidas ou restringidas em determinadas sociedades. Tais valores podem também exercer pressão sobre juízos feitos nos momentos centrais. Os porta-vozes da tradição reconhecem prontamente que tal pressão às vezes é exercida com sucesso, pois os cientistas podem sucumbir a ameaças do poder, a recompensas pela conformidade, ou à sedução do ganho pessoal. Quando isso acontece, os porta-vozes dizem que o entendimento científico foi "distorcido", acrescentando que os procedimentos metodológicos padrão são sensíveis às fontes de distorção, e incorporam dispositivos de resistência a elas (cf. Lacey, 2005a, Cap. 2).

De acordo com tal concepção, as práticas científicas têm uma dimensão social e são afetadas pelo jogo dos valores. Entretanto, as conexões são externas; os valores não são parceiros dialéticos das práticas científicas (cf. Lacey, 2005, seção 5.1), pois não devem interagir nos momentos centrais - e nos casos exemplares não interagem - de maneira indispensável com os valores cognitivos. Isso deixa muitos aspectos do fenômeno científico abertos à investigação histórica e social, porém não afeta a adequação das apreciações teóricas e a correção de decisões metodológicas.

\section{Apreciação gognitiva de teOrias \\ E EXPLICAÇÃO SOGIAL DA AGEITAÇÃO DE TEORIAS}

A fim de evitar a intromissão de valores não-cognitivos em momentos em que são considerados inadmissíveis, é importante distinguir a sustentação cognitiva (racional) de uma teoria (como fornecedora de entendimento de um domínio específico de fenômenos) das condições sob as quais ela adquiriu sustentação ou, em outras palavras, distinguir a questão "Em que bases a teoria (T) é aceita" da questão "O que explica que $\mathrm{T}$ tenha se tornado uma candidata à aceitação, e que as condições para sua investigação tenham se apresentado?” De modo semelhante, Haack distingue "Quão boa é a evidência para uma teoria?" e "Quais são os padrões de conduta da pesquisa científica?" (cf. Haack, 1977). A pesquisa sociológica é apropriada para o segundo tipo de 
questão, porém para o primeiro considera-se que tem relevância epistêmica apenas quando valores não-cognitivos encontram-se de fato entre as bases às quais se apela (explícita ou implicitamente). Nesse caso, a pesquisa social pode explicar a origem das distorções do conhecimento científico; o que também significa, como Haack enfatiza, que, contingentemente, certas condições sociais podem ser necessárias para que teorias adequadamente confirmadas possam ser aceitas. A aceitabilidade de T não é objeto de explicação social, apenas sua aceitação de fato. Apenas quando T é indevidamente aceita a questão importante se torna: por que (causalmente) T foi aceita? A explicação sociológica da aceitação de fato de T não pode obliterar a apreciação cognitiva de T, e uma explicação sociológica dessa apreciação nada nos diz de decisivo a respeito de sua adequação.

\section{VALORES SOGIAIS NOS MOMENTOS GENTRAIS DAS PRÁTICAS GIENTÍFICAS?}

A concepção segundo a qual valores sociais (não-cognitivos) carecem de papéis legítimos nos momentos centrais das práticas científicas - os que dizem respeito à apreciação de teorias e decisões metodológicas - foi contestada e reconsiderada de várias maneiras, por exemplo, por Helen Longino e Philip Kitcher (cf. Longino, 2002a; Kitcher, 2001). Embora esses filósofos estejam de acordo em afirmar que os momentos centrais envolvem inevitavelmente tanto aspectos cognitivos (epistêmicos, racionais) e sociais (não-cognitivos), eles discordam a respeito de como os interesses cognitivos e sociais interagem nesses momentos (cf. Longino, 2002b, 2002c; Kitcher, 2002a, 2002,b). Em particular, eles discordam sobre a relevância dos fatores sociais para a aceitabilidade cognitiva das teorias. ' Será um aspecto constitutivo dos juízos de aceitabilidade cognitiva de teorias o fato de serem feitos sob certas relações sociais que incorporam valores sociais específicos cultivados pelos pesquisadores (Longino)? Ou será que fazer tais juízos (corretos) é apenas uma conseqüência de interações sociais que ocorrem sob essas relações (Kitcher)?

\footnotetext{
1 Eles também discordam a respeito do caráter do pluralismo que ambos afirmam dever estar presente nas práticas científicas e suas metodologias, e do papel da tomada de decisões democráticas nelas. Não discutirei tais questões neste artigo, já tendo feito isso em outras oportunidades, em contextos diferentes (cf. Lacey, 2007, no prelo b).
} 


\section{AGeitaÇÃo DE TEORIAS: UMA GONSEQÜÊNNGIA DE INTERAÇões SOGIAIS}

Minhas observações provêm de uma terceira posição (cf. Lacey, 1999, 2005a, 2008, no prelo a), que a meu ver permite colocar nitidamente em relevo os pontos fortes e fracos das posições de Longino e de Kitcher. Traço uma distinção entre os momentos (1) de adoção de uma estratégia e (2) de apreciação de teorias/confirmação do conhecimento. Esses são os momentos centrais das práticas científicas. Um terceiro momento, da aplicação do conhecimento científico, será importante mais tarde. Adotar uma estratégia envolve identificar os tipos de possibilidades a serem exploradas, e conseqüentemente tomar decisões metodológicas a respeito de questões tais como: "quais restrições devem ser impostas a teorias passíveis de investigação (incluindo as categorias nelas mobilizadas)?" e "quais tipos de dados empíricos devem ser buscados e registrados?"

Enquanto Longino rejeita o que ela denomina uma dicotomia entre o cognitivo e o social, sustento haver uma distinção importante entre valores cognitivos e valores sociais (e outros valores não-cognitivos). Mas não há separação entre eles, pois os valores cognitivos manifestam-se (em teorias) apenas em contextos em que os valores sociais também se manifestam (em práticas e instituições científicas). A distinção é indispensável para o entendimento do lugar dos valores sociais nos momentos centrais (cf. Lacey, 2003a). Os valores cognitivos - que incluem itens como a adequação empírica, o poder explicativo e o poder de antecipar possibilidades abertas aos fenômenos no âmbito de uma teoria (cf. Lacey, 2008, Cap. 3) - são os desideratos de teorias, que são exigidos em vista do objetivo da ciência, o qual assumo ser: gerar e consolidar teorias que expressam entendimento empiricamente apoiado e bem confirmado dos fenômenos (cf. Lacey, 2003a). ${ }^{2}$ Os valores cognitivos não se fundamentam no valor social ou ético de uma teoria, ou em sua significância, ${ }^{3}$ seu potencial de aplicação para promover o florescimento humano, em concepções da boa sociedade, ou em interesses econômicos particulares.

Valores sociais freqüentemente têm papéis legítimos e importantes no primeiro momento, da adoção de uma estratégia (cf. Lacey, 1999, 2003b, no prelo a).4 Neste ponto concordo com Longino. Mas discordo dela que possa haver papéis indispensá-

2 Para uma descrição mais detalhada do objetivo da ciência, ver Lacey, 2007 .

3 Kitcher (2001, Cap. 6) discute de maneira esclarecedora a significância - uma noção com dimensões cognitivas e éticas/sociais - de teorias e resultados científicos.

4. Nem Longino nem Kitcher empregam a noção de estratégia. As concepções de Longino podem ser facilmente parafraseadas em termos de estratégia (cf. Lacey 1999, Cap. 9) e seu "pluralismo" pode ser apresentado como envolvendo um pluralismo de estratégias, podendo cada uma delas ser dialeticamente ligada a valores sociais/éticos. Uma vez adotada uma estratégia, ainda há decisões a serem feitas sobre o foco específico da pesquisa, decisões que 
veis no segundo momento, quando uma teoria é aceita, rejeitada, ou considerada carente de mais pesquisa (cf. Lacey, 1999, Caps. 9, 10). No segundo momento, tudo o que importa é se os valores cognitivos se manifestam à luz dos dados empíricos disponíveis em grau suficientemente alto para tornar injustificável a exigência de pesquisa adicional. Mantenho que uma teoria (a respeito de um domínio especificado de fenômenos) é corretamente aceita se, e apenas se, ela manifesta os valores cognitivos em alto grau em relação a um conjunto apropriado de dados empíricos obtidos por meio da observação desses fenômenos (cf. Lacey, 1999, p. 62-6). Mais precisamente, em grau suficientemente alto para que o conhecimento expresso na teoria possa ser adequadamente considerado estabelecido, não requerendo evidências empíricas adicionais.

Quando uma teoria é corretamente aceita dessa forma, penso que fica adequadamente substanciada uma interpretação "modestamente realista" - o termo é de Kitcher. A evidência fundamenta a afirmação de que a teoria expressa verdades sobre os aspectos dos fenômenos para os quais a teoria é aceita, e sobre algumas possibilidades a que ela dá margem. Estas são "verdades modestas" que envolvem poucos compromissos metafísicos, não implicando a proposição de que fornecem entendimento completo desses fenômenos (ou "do mundo"). Elas são consistentes com outras teorias expressarem outras verdades sobre os fenômenos e suas possibilidades. Embora não sejam “certezas" ("verdades necessárias"), nem em princípio invulneráveis a mais investigações, aceitá-las não consiste apenas em fazer um juízo provisório. A pesquisa realizada fechou a questão na prática. Não há razão (fundamentada em considerações referentes aos valores cognitivos) para submetê-las a pesquisas adicionais, e isso significa que existe uma distinção suficientemente clara entre os resultados praticamente estabelecidos e as hipóteses provisoriamente acolhidas.

Normalmente haverá concordância na comunidade científica relevante a respeito do que é, e o que não é, conhecimento estabelecido. Mas a concordância não é constitutiva do conhecimento estabelecido, embora o fato de haver concordância a respeito de todas as seguintes questões possa fornecer uma boa razão para acreditar que uma teoria é corretamente aceita. Os dados empíricos disponíveis são representativos dos dados que poderiam ser obtidos pela observação dos fenômenos no domínio relevante. À luz de tais dados e de outras teorias já de fato aceitas, a teoria manifesta os valores cognitivos em alto grau em relação a domínios de fenômenos cujos limites foram exaustivamente testados. As críticas foram todas respondidas, isto é, não há propostas de

podem claramente ser influenciadas por valores não-cognitivos. Não está claro para mim se Kitcher atribui um papel para os valores sociais no que identifiquei como o primeiro momento central (pois ele pode negar a existência do pluralismo estratégico), ou apenas posteriormente, na escolha do foco específico da pesquisa. Essa questão é relevante para o tópico da tomada democrática de decisões na ciência. 
projetos (potenciais) de pesquisa cujos resultados possam questionar a teoria - mesmo quando é concedido um período de tempo adequado e há abertura a críticas e testes provenientes de outras perspectivas.

Certamente, é de se esperar que haja discordância sobre tais questões quando um suposto conhecimento não é estabelecido (ver o exemplo na seção "aplicações legitimadoras" abaixo), ou uma teoria não é corretamente aceita. Porém, embora a concordância sobre tais questões forneça boa razão para se acreditar que uma teoria é corretamente aceita, não se segue que seja parcialmente constitutivo de uma teoria corretamente aceita - assim como a razão para acreditar que o último Teorema de Fermat foi provado, a saber, que os especialistas assim o afirmam, não é parcialmente constitutiva de o teorema ser um resultado provado.

\section{AgeitaÇão de teorias:}

\section{PARGIALMENTE CONSTITUÍDAS POR INSTITUIÇÕES SOCIAIS?}

Uma teoria (a respeito de um domínio especificado de fenômenos) corretamente aceita é, repito, uma teoria a respeito da qual se confirmou que manifesta os valores cognitivos em alto grau em relação a um conjunto apropriado de dados empíricos obtidos pela observação desses fenômenos. O fato de ser corretamente aceita é também resultado de um processo social, um resultado de interações entre pesquisadores localizados em várias instituições, as quais incorporam valores considerados apropriados tendo em vista o objetivo das práticas científicas, e promovem certas normas de investigação. Haack (1997) observa que o fato de a ciência ser social desta maneira "é um fator importante contribuindo para sua distinção epistemológica". Note-se: "contribuindo para", não "constitutivo de". O processo social foi moldado e institucionalmente cuidado de modo a produzir teorias corretamente aceitas. Mas não é ser o resultado de qualquer processo social específico, real ou ideal, que é constitutivo de uma teoria corretamente aceita - assim como não é constitutivo de ser um bom automóvel que ele seja produzido por um processo de fabricação confiável. Kitcher concorda com Haack neste ponto, embora discorde dela (e concorde com Longino) sustentando ser importante que a comunidade de pesquisadores reflita uma variedade adequada de valores sociais.

Em contraste, Longino considera o "desempenho satisfatório de certos tipos de interações sociais" como constitutivo de teorias aceitas. Dessas interações participam comunidades de investigação governadas por quatro normas, a saber: locais publicamente reconhecidos para a apreciação de evidências e metodologia, receptividade a críticas, padrões públicos de apreciação e igualdade moderada entre os participantes 
de práticas de pesquisa (cf. Longino, 2002a, p. 129-135). Outro requisito é que essas normas devem ser monitoradas de modo a assegurar que haja escrutínio crítico proveniente de tantas perspectivas quanto possível. O que está em jogo na insistência em "constitutivo de" e não apenas "conseqüência de"? A chave, imagino, é a rejeição por parte de Longino do "realismo modesto" de Kitcher (bem como de qualquer outra forma de realismo científico), uma rejeição que implica a inexistência de juízos a respeito da aceitação correta de teorias, como definidos acima. Em vez disso, ela parece sustentar que a valia cognitiva da aceitação de teorias não pode ser dissociada da comunidade na qual a concordância sobre ela é atingida; e, assim, que qualquer distinção entre resultados estabelecidos e resultados provisórios é relativa à comunidade, refletindo as pressuposições adotadas como substrato da investigação pela comunidade. A relatividade em questão é compatível com a existência de um considerável grau de acordo trans-comunidade. E mesmo, em princípio a longo prazo, pode haver uma única perspectiva teórica compartilhada no mundo todo, porém, os juízos de aceitação não podem ser separados das pressuposições da comunidade de investigação. Para ela, juízos do tipo "T (uma teoria) é corretamente aceita” não existem, mas apenas os do tipo "dadas as pressuposições de uma comunidade (e seus compromissos com um conjunto de valores cognitivos), T deve ser aceita."

Kitcher e eu sustentamos haver teorias corretamente aceitas. É verdade que o juízo de que T é corretamente aceita é feito em uma comunidade de investigação particular, e a comunidade deve ser constituída de acordo com certas normas (talvez as quatro propostas por Longino!) para que seu juízo tenha autoridade. Isso não implica, contudo, que fazer o juízo de que T é corretamente aceita incorpore (implicitamente) referência à comunidade. Compare-se: no momento em que escrevo esta passagem, a árvore em frente da janela de meu escritório perdeu quase todas as suas folhas. Isto é verdade. Vejo que é. Claramente, se eu não estivesse no lugar em que me encontro, não seria capaz de ver isso. Mas vejo, e assim julgo que a afirmação é verdadeira; é merecedora de minha crença e, com base em meu testemunho, é merecedora de crença de modo geral. Porém, minha visão não é constitutiva da veracidade da afirmação; em vez disso, meu reconhecimento de sua veracidade é uma conseqüência de minha visão. A veracidade da afirmação não é relativizada a mim, embora, no momento em que escrevo, apenas eu esteja localizado de modo a reconhecê-la. Isso não relativiza a veracidade da afirmação às condições sob as quais ela pode tornar-se conhecida. Analogamente, a veracidade de "T é corretamente aceita" não é relativizada à comunidade em que estão presentes as condições para que ela se torne conhecida. Naturalmente, fora da comunidade, sua veracidade só pode ser conhecida com base em seu testemunho, assim como o leitor, agora, só pode conhecer a verdade sobre a árvore em frente de minha janela com base em meu testemunho. Não pode ser validamente inferida a 
implicação do fato de que obter conhecimento depende (causalmente) da disponibilidade de certas condições sociais e éticas, para a conclusão de que o conhecimento é relativizado a essas condições, ou que as condições são constitutivas do conhecimento. ${ }^{5}$

Longino não comete essa implicação inválida. Em vez disso, sua posição parece derivar de duas fontes. A primeira já foi indicada: ela nega que juízos do tipo “T é corretamente aceita" sejam possíveis e que possamos dissociar a aceitação de teorias de pressuposições específicas de uma comunidade (talvez não explicitamente articuladas). Mesmo em uma comunidade comprometida com o "escrutínio crítico de propostas teóricas provenientes de tantas perspectivas quanto possível”, o jogo entre os dados empíricos e os valores cognitivos deixa T subdeterminada. Assim, o que uma teoria aceita é (ou o que é o conhecimento científico) é parcialmente constituído por interações, e os valores que elas expressam na comunidade de investigação. Em segundo lugar, Longino questiona se os valores cognitivos podem ser nitidamente distinguidos dos valores sociais e, portanto, ela acolhe a concepção segundo a qual as comunidades de investigação, dependendo dos valores sociais que incorporam, podem identificar os valores cognitivos de maneira diversa (cf. Longino, 1997). Assim, como os valores cognitivos fornecem pontos públicos cruciais de referência no escrutínio de teorias, o que constitui uma teoria aceita é parcialmente dependente dos valores sociais da comunidade de investigação.

$\mathrm{Eu}$ (e Kitcher) discordamos de Longino nos dois pontos. Não vou tratar do segundo ponto aqui; por ora, é suficiente dizer que a concepção dela é conseqüência da falha em separar os dois momentos centrais da atividade científica: a adoção da estratégia e a escolha da teoria (ver Lacey, 1999, Cap. 9 para uma discussão detalhada). Com relação ao primeiro ponto, considere-se o que a meu ver são casos exemplares de resultados científicos estabelecidos, itens de conhecimento científico expressos em teorias corretamente aceitas, como a química molecular, a ação patogênica de vírus e bactérias, a teoria eletrônica aplicada a dispositivos tecnológicos, as explicações da mecânica clássica para os movimentos terrestres. Quando afirmo que são estabelecidos quero dizer que não há situação plausível que possamos descrever em que uma nova perspectiva levaria a um questionamento desses resultados por, digamos, sugerir novas investigações experimentais que possam colocá-los em dúvida. Não digo que não possa haver tais situações. O realismo modesto não lida com necessidades. Não podemos excluir categoricamente que as coisas possam mudar radicalmente, se possibilidades até então inimaginadas e inconcebidas se realizassem. Embora esteja dentro do âmbito da atividade científica a exploração de possibilidades até agora não realiza-

5 Tais condições, entretanto, podem ser constitutivas do valor ético/social, ou da significância do conhecimento. 
das, e de como realizá-las, e o desenvolvimento de nossos poderes conceituais e imaginativos ao fazer isso, não se exige dos juízos científicos que sejam necessários. Reconhecendo isso, não há obstáculo em sustentar - como questão de fato - que tais tipos de resultados mencionados são estabelecidos.

Longino não discute casos concretos como esses em que - Kitcher (2002c) e eu sustentamos - a indeterminação não é uma questão séria. A segunda fonte (acima) pode explicar a relutância dela em fazer as distinções que faço, e assim não separar apreciações de aceitação correta de apreciações do valor social/ético (significância) de uma teoria. Ou talvez a explicação é a existência de teorias, usadas socialmente em oposição a projetos envolvendo valores, que Longino apóia, que foram incorretamente consideradas como estabelecidas. Tais teorias foram aceitas embora não manifestassem os valores cognitivos da maneira adequada e, assim, foram aceitas em parte pelo valor social que tinham à luz dos interesses de seus adeptos. Tais casos sugerem que, pelo menos em alguns domínios de investigação, pode ser importante ter uma pluralidade de valores representados na comunidade científica, refletindo que a aceitação correta de uma teoria pode ser conseqüência de interações moldadas por um conjunto apropriado de valores.

\section{Aplicações legitimadoras}

A maior parte desses resultados estabelecidos são amplamente valorizados pela sociedade; eles levaram a numerosas aplicações na vida social e, provavelmente, para todas as perspectivas de valor realmente adotadas hoje, algumas de suas aplicações são valorizadas. Esse não é o caso de outros resultados estabelecidos. Considere-se :

(1) Plantas de milho transgênico podem ser criadas pela engenharia genética de modo a produzir uma toxina fatal para certa classe de insetos.

Temos aí conhecimento científico estabelecido. Entretanto, (1) não tem valor social (significância) geral; não é aplicável em certos tipos de práticas agrícolas - por exemplo, orgânica e/ou agroecológica - e na verdade sua aplicação ampla ameaçaria a integridade desses tipos de agricultura (cf. Lacey, 2005a, 2006). Por outro lado, (1) tem valor social para o agronegócio contemporâneo e outras instituições, inclinadas a incorporar valores do capital e do mercado, que valorizam intensamente a extensão dos poderes humanos de controlar os objetos naturais a cada vez mais domínios da vida (cf. Lacey, 2005a, Cap. 6; 2006, Cap. 1; no prelo a). Na verdade, a pesquisa que o estabeleceu (1) foi conduzida de acordo com estratégias biotecnológicas que tendem a 
adquirir prioridade porque seus produtos têm tal valor social. Ter tal origem não afeta a aceitabilidade correta de (1), embora fixe limites para seu valor social geral.

Consideremos agora as seguintes alegações:

(2a) Não há riscos ambientais decorrentes do uso de culturas transgênicas que dêem origem a riscos sérios, de dimensões e probabilidade de ocorrência significativas, que não possam ser adequadamente administradas de acordo com regulamentos responsavelmente formulados.

(2b) Não há formas alternativas de agricultura que possam ser empregadas em lugar das formas baseadas em transgênicos, que possam produzir benefícios maiores ou comparáveis.

Embora amplamente defendidas na corrente central da comunidade científica, tais alegações não são estabelecidas; os oponentes continuam a propor projetos de pesquisa que podem produzir resultados que as desafiariam. ${ }^{6}$ Mas, a não ser que (2a) tenha apoio presumível, a legitimidade de aplicar (1), independente da eficácia atestada pelo fato de que consiste em um resultado estabelecido, é posta em dúvida; e (2b) é necessária para legitimar políticas públicas agrícolas que dão prioridade aos transgênicos. Sempre que transgênicos são usados, (2a) e (2b) são tão importantes quanto (1). Porém a pesquisa que estabelece (1) mal começa a ser relevante para (2a) e (2b); as estratégias, que tratam da estrutura molecular dos genomas das plantas, e suas possibilidades de serem modificadas pela engenharia genética, carecem dos recursos necessários para investigar as plantas enquanto componentes de agroecossistemas e, assim, para investigar os impactos sociais e ambientais dos transgênicos, e as possibilidades de alternativas agrícolas baseadas em agroecossistemas sustentáveis.

Espera-se que a comunidade acadêmica se pronuncie sobre (2a) e (2b) (cf. Machamer \& Douglas, 1999). A evidência empírica a favor delas é, em última análise, a falta de evidência contra elas. Evidência contra (2a) consistiria na identificação de fato de um risco ambiental não administrável de magnitude e probabilidade de ocorrência significativas. Mas a presente incapacidade de identificar tais riscos fornece evidência para (2a) apenas no caso da pesquisa relevante ter sido suficientemente realizada.

$\mathrm{O}$ que conta como pesquisa suficiente? Todas as partes no debate reconhecem a existência de riscos. A disputa se dá em torno de seu caráter, de sua extensão, probabilidade, seriedade e possibilidade de ser administrada com base em regulamentos bem formulados. Os defensores dos transgênicos alegam que todos os riscos conhecidos

6 Essa afirmação e o argumento a seguir são elaborados e defendidos em Lacey (2002; 2005a, Cap. 9, 10; 2006, Cap. 4, 5). Nesses trabalhos, a formulação de (2a) e (2b) é mais nuançada. 
podem ser administrados de acordo com os marcos regulatórios disponíveis. Os oponentes apresentam razões teóricas para pensar que há riscos sérios, alguns dos quais ligados às relações socioeconômicas de produção das culturas transgênicas, que apenas a longo prazo tornar-se-ão aparentes: efeitos potencialmente danosos para o meio ambiente, para a manutenção da biodiversidade, para a preservação, regeneração ecriação de agroecossistemas produtivos sustentáveis, e para o sustento dos agricultores pobres. Os defensores afirmam e os oponentes negam que se tenha feito pesquisa suficiente e que, portanto, os oponentes devem assumir o ônus da prova. O que é "suficiente"? Isso depende de quão sérias são as questões éticas envolvidas. Elas são altas para ambos os lados, preocupando-se os oponentes com as ameaças potenciais aos agroecossistemas sustentáveis, enquanto os defensores citam os benefícios potenciais para os agricultores, para as empresas do agronegócio e para as economias nacionais. Os valores dos oponentes estão na base de sua reivindicação de padrões mais elevados de teste - e, embora não possa apresentar a argumentação aqui, também da reivindicação de testes provenientes de uma pluralidade de estratégias (cf. Lacey, 2005a, Cap. 9; 2006, Cap. 4). É importante observar: padrões mais elevados de teste empírico, não que o teste empírico seja irrelevante. A questão não está resolvida. Os defensores endossam (2a), considerando-a apoiada por evidência suficiente para legitimar as culturas transgênicas, enquanto os oponentes endossam sua negação. Ambas as partes recorrem a evidências, mas a padrões e (tipos!) de evidência que refletem juízos de valor conflitantes. Seus respectivos juízos sobre (2a) envolvem assim a consideração de valores tanto cognitivos quanto sociais.

Juízos como esses são com freqüência feitos no decorrer das práticas científicas (cf. Douglas, 2000). Apela-se a eles no momento da aplicação, ou da formação de políticas públicas, embora não sejam simplesmente juízos sobre o valor ético/social da aplicação proposta. Quando atentamos para eles, fica claro haver um tipo de apreciação de teorias que não é redutível à aceitação, à rejeição, ou ao adiamento na dependência de investigações adicionais.

\section{Endossando uma ALEGaÇÃo Gientífica}

Às vezes, a apreciação de teorias envolve o que vou chamar de endossamento de uma teoria (hipótese). Uma comunidade, ou uma pessoa, endossa P quando julga que P manifesta os valores cognitivos em grau suficientemente elevado de tal maneira que aplicála legitimamente, ou agir de maneira informada por $\mathrm{P}$, não requer levar em conta que investigação adicional possa desconfirmar P, ou que - caso isso aconteça - a manifestação dos valores, adotados por diferentes grupos, possa em conseqüência ficar 
ameaçada (cf. Rudner, 1953; Douglas, 2000). Assim, é constitutivo do endossamento de uma teoria (hipótese), que ela não expressa conhecimento estabelecido, que é produzida sob certas condições sociais, cultivadas pelos pesquisadores, as quais incorporam valores sociais específicos. Diferentes comunidades podem endossar proposições incompatíveis sem violar cânone algum da pesquisa empírica e realizar pesquisa com o objetivo de testar o grau de manifestação dos valores cognitivos em teorias (hipóteses). A meu ver, é uma questão aberta se todos os juízos de endossamento podem em princípio, depois de pesquisa empírica exaustiva, vir a ser finalmente substituídos por itens de conhecimento estabelecido.

$\mathrm{Na}$ minha leitura, quando fala da "aceitação" de teorias, Longino não distingue os juízos de aceitação correta dos juízos de endossamento. Penso que a distinção é importante, e que questões de eficácia, item (1), devem ser separadas de questões de legitimidade, itens (2a) e (2b). ${ }^{7}$ Juízos de aceitação correta não são parcialmente constituídos pelas relações sociais (e os valores que expressam) presentes nas comunidades em que são feitos; para os juízos de endossamento isso não vale. Dessa forma, Longino em parte tem razão. ${ }^{\mathbf{8}}$ No início, resumi a concepção amplamente sustentada, segundo a qual os valores sociais não devem desempenhar papel algum na apreciação adequada de teorias e hipóteses científicas, enquanto portadoras de entendimento e conhecimento. Ao passo que Longino contesta frontalmente essa concepção, eu traço uma distinção. Os valores sociais não são parcialmente constitutivos da aceitação correta de uma teoria; mas quando uma teoria não é corretamente aceita, os valores sociais são constitutivos de seu endossamento. ${ }^{9}$

Traduzido do original em inglês por Marcos Barbosa de Oliveira

Hugh LAGeY Professor Titular do Swarthmore College, EUA. hlaceyı@swarthmore.edu

\footnotetext{
7 Embora não faça explicitamente essa distinção, Kitcher discute as possíveis implicações éticas e sociais da biotecnologia médica de maneira tal que entrelaça a investigação empírica e sua visão ética liberal num sentido amplo (cf. Kitcher, 1997).

8 Isso tem implicações para o pluralismo na comunidade científica que não podem ser discutidas aqui. 9 Este artigo é a tradução de uma versão revista de Lacey (2005b).
} 


\title{
Aspegtos Gognitivos e sogiais das práticas Gientíficas
}

\begin{abstract}
Is it constitutive of making judgments of the cognitive acceptability of theories that they are made under certain social relations that embody specific social values that have been cultivated among investigators (Helen Longino)? Or is making sound judgments of this kind just a consequence of social interactions that occur under these relations (Philip Kitcher)? While generally endorsing the latter view, I make a distinction, not made by the philosophers under discussion, between sound acceptance and endorsement of a theory, and argue that Longino's view applies to endorsement.
\end{abstract}

KEYwords • Cognitive values. Social values. Objectivity. Longino. Kitcher.

Scientific theory appraisal. Scientific methodology.

\section{REFERÊNGIAS BIBLIOGRÁFIGAS}

Douglas, H. Inductive risk and values in science. Philosophy of Science, 67, p. 559-79, 2000.

Dupas, G. (Org.). Tensões entre meio-ambiente e crescimento econômico. São Paulo: Unesp. No prelo.

HAAck, S. Science as social? - yes and no. In: Nelson, L. H. \& Nelson, J. (Ed.). Feminism, science, and the philosophy of science. Dordrecht: Kluwer, 1997 p. 79-93.

Kitcher, P. The lives to come: the genetic revolution and human possibilities. New York: A Touchstone Book, 1997 .

. Science, truth and democracy. New York: Oxford University Press, 2001.

The third way: reflections on Helen Longino's "The fate of knowledge". Philosophy of Science, 69,

p. 549-59, 2002a.

. Reply to Helen Longino. Philosophy of Science, 69, p. 569-72, 2002b.

A case of misrepresentation. Science, 295, p. 1.466, 2002c.

LACEY, H. Is science value free? Values and scientific understanding. London: Routledge, 1999.

Assessing the value of transgenic crops. Science and Engineering Ethics, 8, p. 497-511, 2002.

Existe uma distinção relevante entre valores cognitivos e sociais? Scientiae Studia 1, 2, p. 121-4.9, $2003 \mathrm{a}$.

. The behavioral scientist qua scientist makes value judgments. Behavior and Philosophy, 31, p. 20923, 2003b.

.Values and objectivity in science, and current controversy about transgenic crops. Lanham, MD: Lexington, 2005 a.

. On the interplay of the cognitive and the social in scientific practices. Philosophy of Science, 72 ,

p. $977-88,2005$ b.

. A controvérsia sobre os transgênicos. Questões científicas e éticas. Aparecida: Idéias e Letras, 2006.

. On the aims and responsibilities of science. Principia, 11, p. 45-62, 2007.

Valores e atividade científica 1. São Paulo: Associação Filosófica Scientiae Studia/Editora 34, 2008.

Valores e atividade científica 2. São Paulo: Associação Filosófica Scientiae Studia/Editora 34. No prelo a.

Crescimento econômico, meio-ambiente e sustentabilidade social: a responsabilidade dos cien-

tistas e a questão dos transgênicos. In: DupAs, G. (Org.). Tensões entre meio-ambiente e crescimento econômico. São Paulo: Editora Unesp. No prelo b.

Longino, H. E. Cognitive and non-cognitive values in science: Rethinking the dichotomy. In: NeLson,

L. H. \& Nelson, J. (Ed.). Feminism, science, and the philosophy of science. Dordrecht: Kluwer, 1997. p. $39^{-} 5^{8}$.

. The fate of knowledge. Princeton: Princeton University Press, 2002a. 
Longino, H. E. Science and the common good: thoughts on Philip Kitcher's "Science, truth and democracy". Philosophy of Science, 69, p. 56o-8, 2002b.

. Reply to Philip Kitcher. Philosophy of Science, 69, p. $57^{3-7}$, 2002c.

Machamer, P. \& Douglas, H. Cognitive and social values. Science and Education, 8, p. 36-41, 1999.

Nelson, L. H. \& Nelson, J. (Ed.). Feminism, science, and the philosophy of science. Dordrecht: Kluwer, 1997.

Rudner, R. The scientist qua scientist makes value judgments. Philosophy of Science, 20, p. 1-6, $195^{3}$.

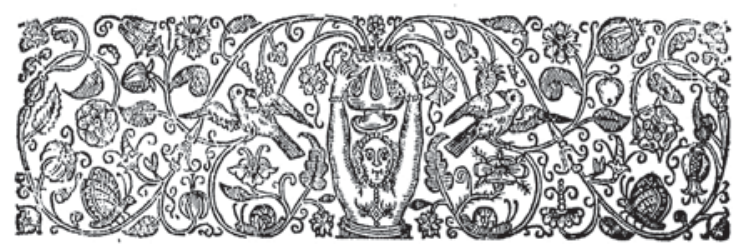

